\title{
The Energy Transition's Impact on the Accumulated Average Efficiency of Large Hydrogenerators
}

This paper was downloaded from TechRxiv (https://www.techrxiv.org).

\section{LICENSE}

CC BY 4.0

SUBMISSION DATE / POSTED DATE

$19-10-2021 / 21-10-2021$

\section{CITATION}

Karekezi, Yannick Cyiza; Øyvang, Thomas; Nøland, Jonas Kristiansen (2021): The Energy Transition's Impact on the Accumulated Average Efficiency of Large Hydrogenerators. TechRxiv. Preprint. https://doi.org/10.36227/techrxiv.16834195.v1

$\mathrm{DOI}$

10.36227/techrxiv.16834195.v1 


\title{
The Energy Transition's Impact on the Accumulated Average Efficiency of Large Hydrogenerators
}

\author{
Yannick Cyiza Karekezi, Student Member, IEEE, Thomas Øyvang, Member, IEEE, \\ and Jonas Kristiansen Nøland, Member, IEEE
}

\begin{abstract}
The energy transition is aimed to take advantage of the operational flexibility of hydropower to extend the integration of intermittent renewable sources. Consequently, the hydrogenerators will have to operate in regimes far away from their designed best-point operation. In order to accurately assess the impact, this paper presents a useful approach to determine the overall operating efficiency of synchronous generators under intermittent operation. An accumulated average efficiency (AAE) model is proposed and compared against an alternative approach; the weighted average efficiency (WAE) model. It is found that the WAE approach produces unrealistic low efficiencies when the generator operates in synchronous condenser mode (SCM) for long periods. In general, the AAE supersedes the WAE for all the different load distributions that were investigated. This was further illustrated by a worked example and by constructing more complex load distributions. A load distribution dominated by SCM yields a difference as high as $33.18 \%$, while an even distribution deviates $1.43 \%$ in their respective efficiencies. Finally, a yearly on-site measurement of our studied $103 \mathrm{MVA}$ generator's concentrated load distribution revealed a discrepancy of $0.67 \%$, which is a significant deviation considering what the operating regime would mean in terms of economic implications.
\end{abstract}

Index Terms-Synchronous machines, saturation modeling, efficiency modeling, loss measurement.

\section{NOMENCLATURE}

$\Delta t_{i} \quad$ Discrete time interval for a load point, $[h]$ or $[s]$

$\delta \quad$ Rotor loading angle, $[\mathrm{rad}]$ or $\left[{ }^{\circ}\right]$

$\eta \quad$ Generator's operation point efficiency, $[p u]$ or $[\%]$

$\eta_{a} \quad$ Accumulated average efficiency (AAE), [pu] or [\%]

$\eta_{n} \quad$ Generator's nominal efficiency, $[p u]$ or [\%]

$\eta_{w} \quad$ Weighted average efficiency (WAE), [pu] or [\%]

$\mathcal{E}_{g} \quad$ Total fictive induced generator voltage, $[p u]$ or $[\mathrm{V}]$

$\mathcal{E}_{p} \quad$ Induced voltage behind potier reactance, $[p u]$ or $[\mathrm{V}]$

$\stackrel{P}{P} \quad$ Mean power, $[p u]$ or $[k W]$

$\bar{P}_{\text {loss }} \quad$ Mean power loss, $[p u]$ or $[k W]$

$\theta \quad$ Angle behind the potier reactance, $[\mathrm{rad}]$ or $\left[{ }^{\circ}\right]$

$\varphi \quad$ Power factor angle, $[\mathrm{rad}]$ or $\left[{ }^{\circ}\right]$

$A_{i} \quad$ Weighting factor for an operation point, [pu] or [\%]

$b_{v} \quad$ Slope constant of the generator's air gap line curve

$C_{m} \quad$ Saturation constant for the generator's saturation curve

$E \quad$ Generator's accumulated energy production, [ $G W h$ ]

$E_{\text {loss }} \quad$ Generator's accumulated energy losses, [GWh]

Manuscript submitted June 15, 2021 (Corresponding author: Yannick Cyiza Karekezi).

Y. C. Karekezi and J. K. Nøland are with the Norwegian University of Science and Technology (NTNU), Trondheim, Norway (e-mail: yannickk@stud.ntnu.no; jonas.k.noland@ntnu.no) and also with the University of South-Eastern Norway (USN), Porsgrunn, Norway.

T. Øyvang is with the University of South-Eastern Norway (USN), Porsgrunn, Norway (e-mail: thomas.oyvang@usn.no).

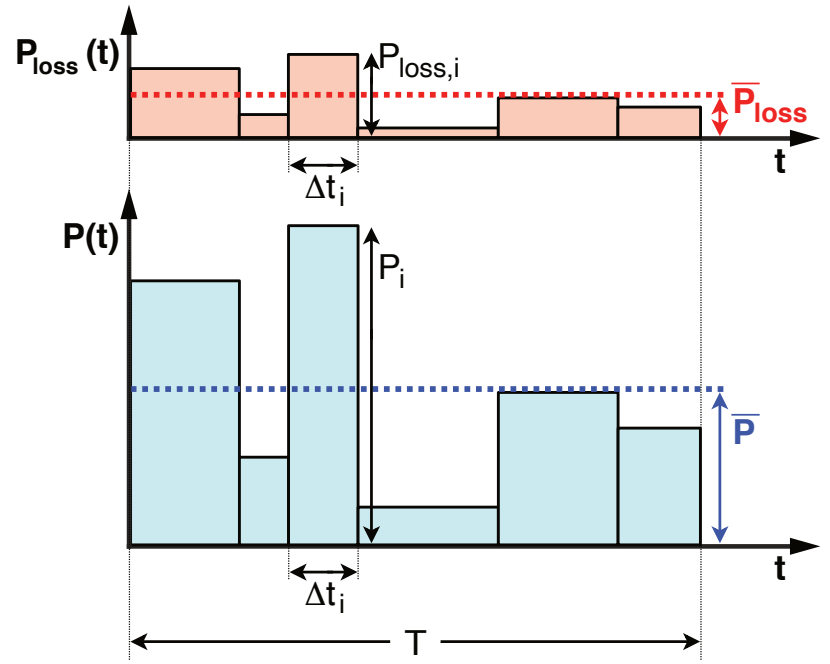

Fig. 1. Generic load cycling sequence for accumulation of the generator's energy loss $\left(E_{\text {loss }}\right)$ and energy generation $(E)$ over time formulated by discrete time intervals. $E_{\text {loss }}$ is equal to the sum of all red areas, while $E$ is the sum of all blue areas. The mean power loss $\left(\bar{P}_{\text {loss }}=E_{\text {loss }} / T\right)$ and the mean power generation $(\bar{P}=E / T)$ are also indicated.

$I_{a} \quad$ Stator armature current, $[p u]$ or $[A]$

$I_{f} \quad$ Rotor field current, $[p u]$ or $[A]$

$k \quad$ Slope constant for approximating the generator' saturation curve in the air gap line region

$m \quad$ Saturation curve's exponential constant

$P \quad$ Generator's active power, $[p u]$ or $[M W]$

$P_{a} \quad$ Stator armature winding resistive loss, $[p u]$ or $[k W]$

$P_{b e} \quad$ Bearing loss, $[p u]$ or $[k W]$

$P_{b r} \quad$ Rotor brush loss, $[p u]$ or $[k W]$

$P_{c} \quad$ Stator armature iron core loss, $[p u]$ or $[k W]$

$P_{e x} \quad$ Excitation system loss, $[p u]$ or $[k W]$

$P_{f} \quad$ Rotor field winding resistive loss, $[p u]$ or $[k W]$

$P_{\text {loss }} \quad$ Generator's total losses, $[\mathrm{pu}]$ or $[\mathrm{kW}]$

$P_{s} \quad$ Stator stray load loss, $[p u]$ or $[k W]$

$P_{w f} \quad$ Windage and friction loss, $[p u]$ or $[k W]$

$Q \quad$ Generator's reactive power, $[p u]$ or $[M V A r]$

$R_{a} \quad$ Stator armature resistance, $[p u]$ or $[\Omega]$

$S \quad$ Generator's apparent power, $[p u]$ or $[M V A]$

$U_{a} \quad$ Stator armature terminal voltage, $[p u]$ or $[V]$

$X_{d} \quad$ Direct axis synchronous reactance, $[p u]$ or $[\Omega]$

$X_{p} \quad$ Potier reactance, $[p u]$ or $[\Omega]$

$X_{q} \quad$ Quadrature axis synchronous reactance, $[p u]$ or $[\Omega]$

\section{INTRODUCTION}


$\mathbf{O}$ VER the last decade, the load cycling intervals of large hydropower plants have changed fundamentally from rated conditions to a diverse set of operating points. As a result of a significant integration of intermittent renewable energy sources (RES) to the grid, the classical generators have responded more often to dispatch the fluctuations in both voltage and power [1]-[3]. These operating regimes bring new economic costs into consideration, as the efficiency now becomes a significant differentiator. By convention, the nominal efficiency is usually taken for granted.

This paper's primary focus is how the energy transition affects the hydrogenerator units in terms of a more flexible operational regime. Future operating regimes imply frequent step changes in active and reactive power production, and several start-stop cycles during the day and week [4]-[7], depending on the RES's weather pattern. It also implies running the generators in synchronous condenser mode (SCM), providing intermittent power reserves, buffers, and rotating inertia. Currently, there are few concrete plans from the US and European governments to reconstruct the present grid topology to adapt for a full-scale energy transition. In essence, it implies that the bulk power plants must handle the increasing volatility of the power grid when alternative largescale energy storage solutions are not readily available. It is, therefore, a desire to design robust hydrogenerators for the future, taking their operational burden and the potential load fluctuations into account. Most of the generators today are not designed for these kinds of operational regimes as they are conventionally specified for a constant duty mode, and a nominal operating point [8]. Historically, the synchronous machine has operated in load points limited and concentrated around a relatively small region of the capability diagram. The reactive power has been varying slightly around a unity power factor, with reactive power generation dominating. In the future, this concentrated distribution is projected to be transformed into a more evenly distributed distribution pushing closer to the boundaries of the capability diagram. This effect is highlighted in [5]-[7], depicting changes as a result of the German "Energiwende." In addition, the capability diagram's maximum reactive limits might be extended further for extra reactive power reserves during shorter periods to provide enhanced grid voltage security [9]. Moreover, in periods of excess water, extra frequency support can be provided at peak hours if allowing an overloaded active power capability [10].

The ever-increasing introduction of RES results is intensified when hydropower is connected to larger geographical regions [11]. The increasing prevalence of these kinds of operational regimes requests the need for calculation models that can accurately quantify the overall impact for hydrogenerators [7], in addition to the operational burden at the turbine-side as well [12], [13]. The calculation model weighted average efficiency (WAE) offers a viable solution to quantify the RES' impact on hydro generators [1] -[3]. The computational scheme is a sampling average approximation approach to obtain the overall operating efficiency of generators varying over different loading conditions during a finite time period. However, the WAE has one primary weakness; it weights the efficiency for one loading point at a time and not the

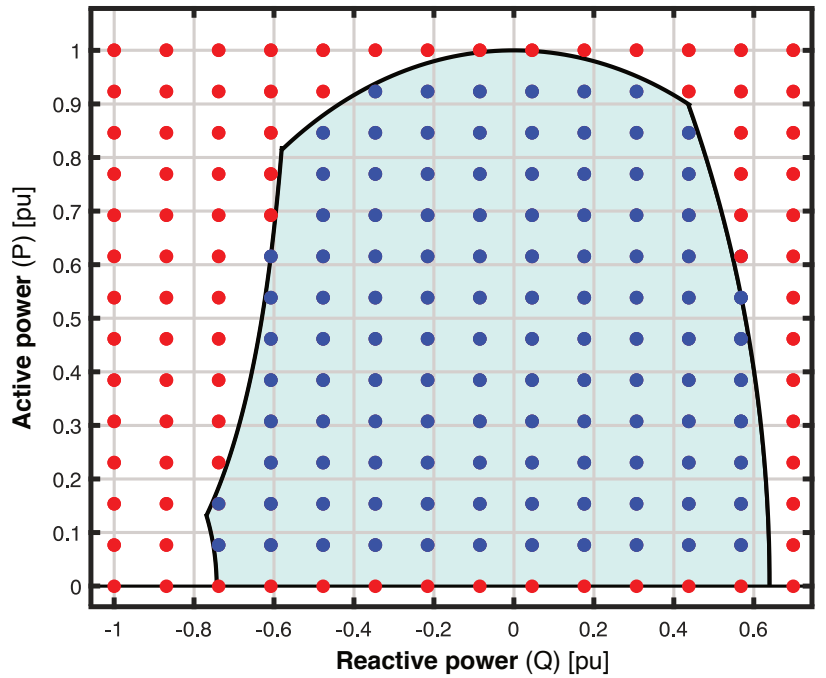

Fig. 2. Example of 110 blue uniformly distributed load points inside the capability diagram for the 103 MVA hydrogenerator considered in this paper. Red points are outside of the capability diagram.

accumulation of the loading points. This means that if the generator is operated purely as a synchronous condenser ( i.e., $P=0 \mathrm{pu}$ ) for a long time, one can get a large dataset of samples of zero efficiencies in the summation of average efficiencies. This reduces the WAE considerably.

This paper presents the concept of accumulated average efficiency (AAE) as a new and useful method to compute the mean efficiency of synchronous generators when they frequently vary their operating conditions. An illustration of the concept is depicted in Fig. 1 . but further described in Section III. The method is compatible with both exact load points or load-grid distributions clustered in discrete points, as depicted in Fig. 2 The proposed AAE approach will be compared against the already established WAE [1]-[3].

In order to accurately predict the needed field current during different load operations, a different saturation modeling approach is utilized, taken as an alternative to what has already been proposed by Bortoni et. al. for efficiency modeling [1]. Our calculations, simulations, and post-processing of measurements are all conducted in the MATLAB numerical environment. In order to confirm the predictions made by the efficiency model, on-site efficiency recordings were done at different load operations to ensure that the model could predict the efficiency for the major portions of the capability diagram. This enabled us also to make artificial load distributions to predict the implications of the energy transition's rapid increase in RES. The peculiar case of SCM-dominated operation was considered as the worst case. Moreover, real-world production data covering a whole year for the considered hydrogenerator was post-processed to analyze the implications of the presentday load operations.

The paper is organized as follows. Section II reviews the power loss modeling and formulates the segregation of loss to be compatible with the proposed AAE. Then, in Sections III and IV, the proposed efficiency and saturation modeling approaches are described. Finally, Section V presents the main 
results from our handpicked case studies before Section VI concludes our findings.

\section{Power Loss Modeling}

This section briefly presents the loss modeling employed in this paper. For clarity, the nomenclature describes all the variables from the paper's beginning. The segregation of the loss components is needed for the efficiency modeling formulation but is independent of the chosen approach. Its general formulation has already been well described in [1]. Differently from the work of Bortoni et. al. [1] is the explicit expression of the total losses $\left(P_{\text {loss }}\right)$ to make the formulation compatible with our proposed AAE approach. Moreover, this paper also expresses a compressed formulation of the loss modeling in eqs. (2)-(5), merging the armature and strayload losses [14], and bringing the field winding and brush losses together. Moreover, the exciter loss is considered as directly proportional to the field current [15]. As usual, the bearing, windage, and friction losses appear as constant loss components. In addition, the iron core loss [16] is assumed as a constant since the armature voltage $\left(U_{a}\right)$ is kept close to $1 \mathrm{pu}$, even though the flux angle can have a minor effect. The grid voltage is constrained to be between 0.95 and $1.05 \mathrm{pu}$ in many grid codes [17], [18], implying that $P_{c}$ will vary $-9.75 \%$ to $+10.25 \%$ from its base value. Hereafter, $P_{c}$ is considered as a constant value, assuming $U_{a}=1 \mathrm{pu}$. This also implies that the per-unit armature current can be approximated as

$$
I_{a}=\frac{\sqrt{P^{2}+Q^{2}}}{U_{a}} \approx \sqrt{P^{2}+Q^{2}} .
$$

The field current $\left(I_{f}\right)$ prediction is less straightforward and is separately described in Section IV

The rated quantities of the active power losses are tagged with "*". Moreover, "*" is also used to indicate the nominal values of the armature current $\left(I_{a}^{*}\right)$ and the field current $\left(I_{f}^{*}\right)$, respectively. The load-dependent equations and assumptions for the iron core and excitation losses are not explicitly included in this manuscript but details can be found in [1].

$$
\begin{gathered}
P_{a}+P_{s}=\left(P_{a}^{*}+P_{s}^{*}\right)\left(\frac{I_{a}}{I_{a}^{*}}\right)^{2} \\
P_{f}+P_{b r}=\left(P_{f}^{*}+P_{b r}^{*}\right)\left(\frac{I_{f}}{I_{f}^{*}}\right)^{2} \\
P_{l o s s}=P_{a}+P_{s}+P_{c}+P_{f}+P_{b r}+P_{e x}+P_{b e}+P_{w f} \\
\eta=\frac{P}{P+P_{l o s s}}
\end{gathered}
$$

Eqs. (2)-(5) need to be evaluated for an exact load load operation point, e.g., $0.9 \mathrm{pu}$ active power and $0.436 \mathrm{pu}$ reactive power, which is the rated load point. In reality, all possible operating points are continuous. This means that the power does not jump from one power level to another. Fig. 1 presents the continuous power as time interval for specific load points. This is taken as an approximation of the continuous power, where power-ramping profiles are neglected. The same time intervals can also be visually represented in a P-Q diagram, where collections of the measured load points are clustered into discrete load points with a given probability of occurrence ( $\left.\frac{\text { duration }}{\text { totalime }}\right)$ using a 2D histogram [1]. In Fig. 2, an example of these discrete load points is defined in a grid structure inside the capability diagram. In a real case study, each discrete points' probability is determined by its proximity to actual measured load points. Therefore one can determine the probability ( $\left.\frac{\text { duration }}{\text { totaltime }}\right)$ for the predefined load points based on the density of the measured load points and their duration recorded around these clustered points. Moreover, the red points outside the indicated capability diagram violate the machine's capacity limits and are therefore set to zero probability. A discrete point with high probability reveals that a large number of measured machine loading intervals occur in its proximity.

The probability of the occurrence for a particular loadinterval can be understood from Fig. 11, where

$$
A_{i}=\frac{\Delta t_{i}}{T} \text {. }
$$

\section{EFFICIENCY MODELING}

The calculation of the efficiency of several discrete points can then be used to obtain non-concentric curves that map the studied machine's efficiency characteristics at different load operations. This section takes our adapted power loss modeling on board to formulate a modeling approach for the overall operating efficiency. First, the challenges with the alternative WAE are presented before the proposed AAE is derived. It is worth noting that the basics of the WAE have already been well explored and studied in [1].

\section{A. Weighted Average Efficiency (WAE)}

The main obstacle with the WAE formulation lies in the efficiency definition, which has severe consequences for certain operational regimes such as the synchronous condenser mode (SCM) of operation. In the WAE formulation, the efficiency is calculated for every operating point and multiplied with its corresponding weight, where all weighted efficiencies are finally summed up to an average efficiency. The WAE can be expressed in the continuous time frame using eq. (7), which is further explained in [1]. The WAE in the finite time intervals can be expressed using eq. (8), where the efficiency of different operating points is weighted depending on their time duration over a period $T$. Alternatively, including its respective index ( $i$ ) for finite time intervals, the WAE could be formulated with eq. (9).

$$
\begin{gathered}
\eta_{w}=\frac{1}{T} \int_{0}^{T} \eta(t) d t \\
\eta_{w}=\sum_{i=1}^{n} \eta_{i} \frac{\Delta t_{i}}{T}=\sum_{i=1}^{n} \eta_{i} A_{i}=\eta_{1} A_{1}+\eta_{2} A_{2}+\ldots+\eta_{n} A_{n} \\
\eta_{w}=\sum_{i=1}^{n} \frac{P_{i}}{P_{i}+P_{\text {loss }, i}} A_{i}
\end{gathered}
$$


From the expressions above, the WAE is seen to be directly proportional to the efficiency of the weighted load points. I.e., if one-third of the given dataset's efficiency is zero (e.g., under SCM operation), then the WAE gets reduced by $\frac{1}{3}$. Consequently, it also means that the WAE can not be higher than $66 \%$ when the generator operates $\frac{1}{3}$ of its running time as a synchronous condenser. This can be illustrated by inserting eq. (10) as an element into eq. (8).

$$
\eta_{s c m}=\frac{P_{s c m}}{P_{s c m}+P_{s c m, l o s s}}=\frac{0}{0+P_{s c m, l o s s}}=0 \%
$$

Eq. (10) clearly shows that there is an unclear representation of the inefficiency as the losses are not accounted for when the generator runs in SCM of operation. If one imagines that the eq. 10 occurs $\frac{1}{3}$ of the time during its yearly operation, it would mean that one has not accurately quantified the actual machine losses during $\frac{1}{3}$ of the generators' operating time. Let us consider a simple example where the generator operates in two distinct operating points over a full period, where the generator operates at rated conditions $\frac{2}{3}$ of its time, $\Delta t$ (i.e., $\frac{\Delta t}{T}=\frac{2}{3}$ ), with efficiency $\eta_{n}$, and as a synchronous condenser during $\frac{1}{3}$ of its operating time, $T-\Delta t$ (i.e., $1-\frac{\Delta t}{T}=\frac{1}{3}$ ). Insertion of these conditions into eq. (7) yields that the WAE is expressed as

$$
\eta_{\mathrm{w}}=\frac{1}{T}(\eta_{n} \cdot \underbrace{\Delta t}_{=\frac{2}{3} T}+\underbrace{\eta_{s c m}}_{=0} \cdot(T-\Delta t))=\left(\frac{2}{3}\right) \eta_{n},
$$

yielding a WAE two-thirds of the nominal efficiency.

\section{B. Accumulated Average Efficiency (AAE)}

The proposed AAE follows an entirely different calculation procedure, as illustrated in Fig 1 . The total accumulated energy generation $(E)$ and energy losses $\left(E_{l o s s}\right)$ are the basis for the AAE, as expressed in eq. (12). This approach merely takes the accumulated $E$ and $E_{\text {loss }}$ into account, which minimizes the influence of very low efficiencies under SCM operation.

$$
\eta_{a}=\frac{E}{E+E_{\text {loss }}}=\frac{\int_{0}^{T} P(t) d t}{\int_{0}^{T} P(t) d t+\int_{0}^{T} P_{\text {loss }}(t) d t}
$$

In the finite time formulation, the AAE first starts by computing the actual active power losses $\left(P_{\text {loss }, i}\right)$ for each the discrete time interval $\left(\Delta t_{i}\right)$ given by index $i$ for a given load point $P_{i}$. Then, the sum of all the actual power elements $\left(P_{i}\right.$ and $\left.P_{\text {loss }, i}\right)$ are multiplied individually by the time duration $\left(\Delta t_{i}\right)$ to obtain average values or expected values in terms of accumulated energy ( $E$ and $E_{\text {loss }}$ ), as formulated in eqs. (13) and (14), where the total time $(T)$ is given in eq. (15).

$$
\begin{aligned}
& E_{\text {loss }}=\sum_{i}^{n} P_{\text {loss }, i} \Delta t_{i} \\
& =P_{l o s s, 1} \Delta t_{1}+P_{\text {loss }, 2} \Delta t_{2}+\ldots+P_{l o s s, n} \Delta t_{n} \\
& E=\sum_{i}^{n} P_{i} \Delta t_{i}=P_{1} \Delta t_{1}+P_{2} \Delta t_{2}+\ldots+P_{n} \Delta t_{n}
\end{aligned}
$$

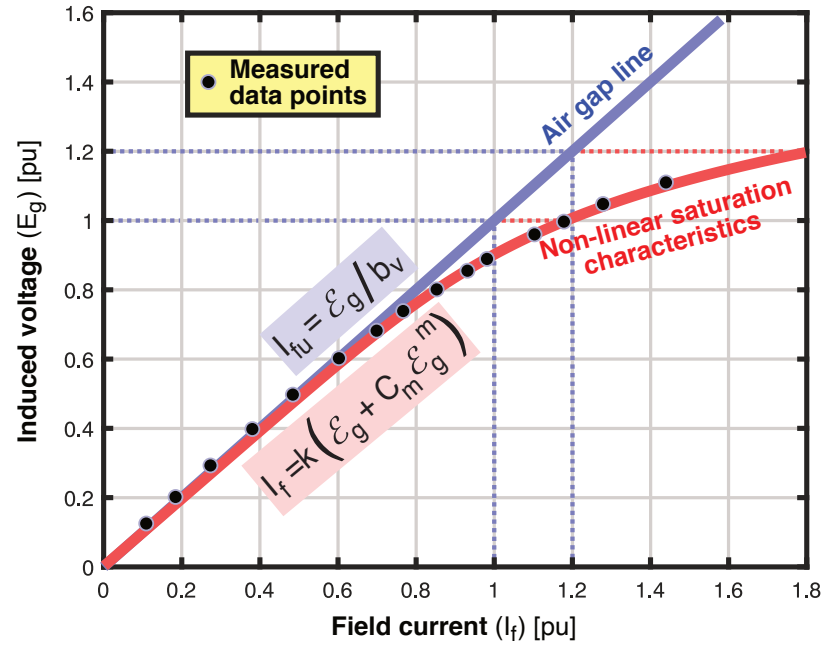

Fig. 3. The per-unit saturation curve of the $103 \mathrm{MVA}$ synchronous machine aligned with measured operating points measured at no-load conditions and rated speed of $500 \mathrm{rpm}$. This machine is considered as a case study in Section $\mathrm{V}$ The air gap line curve and the non-linear staturation characteristics refers to eqs. 21) and 22, , respectively (coefficients are given in Table 1 . The base field current and line voltage is $525.15 \mathrm{~A}$ and $11 \mathrm{kV}$.

$$
T=\sum_{i}^{n} \Delta t_{i}=\Delta t_{1}+\Delta t_{2}+\ldots \Delta t_{n}
$$

In order to convert the expressions into weighted sums, eqs. (13) and (14) are modified into the mean power generation $(P)$ and the mean power loss $\left(\bar{P}_{\text {loss }}\right)$ in eqs. 16$)$ and 17 , respectively.

$$
\begin{aligned}
\bar{P}=\frac{E}{T} & =\sum_{i}^{n} P_{i} A_{i}=P_{1} A_{1}+P_{2} A_{2}+\ldots P_{n} A_{n} \\
\bar{P}_{\text {loss }} & =\frac{E_{\text {loss }}}{T}=\sum_{i}^{n} P_{\text {loss }, i} A_{i} \\
& =P_{\text {loss }, 1} A_{1}+P_{\text {loss }, 2} A_{2}+\ldots P_{\text {loss }, n} A_{n}
\end{aligned}
$$

The normalization ensures that the sum of the weights $\left(A_{i}\right)$ is equal to unity, yielding

$$
1=\sum_{i}^{n} \frac{\Delta t_{i}}{T}=\sum_{i}^{n} A_{i}=A_{1}+A_{2}+\ldots A_{n} .
$$

The time-based and the weight-based formulations of the AAE are provided in eqs. (19) and 20, respectively.

$$
\begin{gathered}
\eta_{a}=\frac{E}{E+E_{\text {loss }}}=\frac{\sum_{i}^{n} P_{i} \Delta t_{i}}{\sum_{i}^{n} P_{i} \Delta t_{i}+\sum_{i}^{n} P_{\text {loss }, i} \Delta t_{i}} \\
\eta_{a}=\frac{\bar{P}}{\bar{P}+\bar{P}_{\text {loss }}}=\frac{\sum_{i}^{n} P_{i} A_{i}}{\sum_{i}^{n}\left(P_{i}+P_{\text {loss }, i}\right) A_{i}}
\end{gathered}
$$

\section{Magnetic Saturation Modeling}

As mentioned above, the generator loading condition impacts the field current $\left(I_{f}\right)$, where loss components apply, as expressed in eq. (3). Consequently, the machine's magnetic saturation plays a role in determining the losses and the efficiency accurately. In other words, this means that one 
cannot assume that the generator's field current $I_{f}$ is directly proportional to the induced voltage $\mathcal{E}_{g}$, as in the linear region.

The open-circuit characteristics (OCC) are given by the manufacturer's datasheet and are in line with the measurements presented in Fig. 3, for the particular machine studied in this paper. A mathematical relation is set up to fit the measured data points of the saturation curve. The OCC is converted to a per-unit system, where the field current $\left(I_{f}\right)$ is scaled by the nominal field current of the air gap line characteristics. For this particular case, the $I_{f 0, b a s e}$ is $525.15 \mathrm{~A}$. The rated current $\left(I_{f}\right)$ given in Table II] will then have a normalized value of $2.028 \mathrm{pu}$, with a physical value of $1065 \mathrm{~A}$.

A wide range of methods is applicable to express the OCC in mathematical terms. Our handpicked eq. (22) that fits the data has its coefficients presented in Table 1 Beneficially, only two values need to be tuned, $C_{m}$ and $k$, that are arbitrary constants. The function stems from the generator fundamentals presented by Machowski [19], based on earlier works on saturation. Our extension is using the proposed constant $k$ in this paper, extending the classical formulation to make it compatible with the air gap line linear region, predicted by eq. 221. As a result, eq. 22 needs no arbitrary saturation threshold as it can approximate the OCC of the linear region and the saturation region, simultaneously. Usually, the slope of the air gap line is equal to $1 \mathrm{pu}$, which is formulated in eq. (21), if $b_{v}$ is set to $1 \mathrm{pu}$.

$$
\begin{gathered}
I_{f u}=\frac{\mathcal{E}_{g}}{b_{v}} \\
I_{f}=k\left(\mathcal{E}_{g}+C_{m} \mathcal{E}_{g}^{m}\right)
\end{gathered}
$$

The procedure is as follows. First, the coefficient $m$ is selected as either 7 or 9 . Then, the two other constants, $k$, and $C_{m}$ are found from a fitting procedure to obtain the red curve in Fig. 3. An alternative approach is found in Bortoni et. al. [1] that uses a fourth-order polynomial regression of the non-linear saturation characteristic to provide five polynomial coefficients. This method has a high accuracy for expressing the saturation curve but needs more arbitrary valued coefficients and a separate equation for the air gap line below a certain threshold. This paper takes a different path, where eq. (22) applies to the whole domain of the OCC, making it computationally user-friendly, less sensitive to parameter values and arbitrary thresholds. Based on the Potier method, obtaining $I_{f}$ is formulated differently, as given in eq. (23).

$$
I_{f}=\frac{\mathcal{E}_{g}-\mathcal{E}_{p}}{b_{v}}+k\left(\mathcal{E}_{p}+C_{m} \mathcal{E}_{p}^{n}\right)
$$

Both $\mathcal{E}_{g}$ and $\mathcal{E}_{p}$ are found from $I_{a}$ in eq. (1) and the power factor angle given by $\varphi=\tan ^{-1}(Q / P)$. $\mathcal{E}_{g}$ is the fictive induced voltage behind $X_{d}$ and $X_{q}$, while $\mathcal{E}_{p}$ lies behind $X_{p}$, as explained in [20], [21], and further applied in [1]. However, before obtaining $\mathcal{E}_{g}$ and $\mathcal{E}_{p}$, their respective voltage angles, $\delta$ and $\theta$, are often estimated, if not an all-in-one complex formulation is utilized. The saturation modeling is further validated under full-load condition in Section $\mathrm{V}-\mathrm{A}$, extending the preliminary no-load verification of Fig. 3 .
TABLE I

COEFFICIENTS USED For the FITTING EQs. 21, and 22, IN Fig. 3

\begin{tabular}{cccccc}
\hline \hline Symbols & $\mathbf{b}_{\mathbf{v}}$ & $\mathbf{C}_{\mathbf{m}}$ & $\mathcal{E}_{g}$ & $\mathbf{m}$ & $\mathbf{k}$ \\
\hline Values & 1 & 0.160 & $0-1.8$ & 7 & 1.0308 \\
\hline \hline
\end{tabular}

TABLE II

Key QuANTITIES OF THE STUdied Hydrogenerator

\begin{tabular}{clc}
\hline \hline Symbol & Description & Value \\
\hline$S_{b}$ & Base apparent power & $103 \mathrm{MVA}$ \\
$\cos (\varphi)$ & Power factor & 0.90 \\
$\eta_{n}$ & Measured rated efficiency & $98.834 \%$ \\
$U_{t}$ & Nominal armature voltage & $11 \mathrm{kV}$ \\
$I_{t}$ & Nominal armature current & $5406 \mathrm{~A}$ \\
$I_{f}$ & Rated field current & $1065 \mathrm{~A}$ \\
$f$ & Nominal frequency & $50 \mathrm{~Hz}$ \\
$p$ & Number of poles & 12 \\
$n$ & Nominal speed & $500 \mathrm{rpm}$ \\
\hline \hline
\end{tabular}

TABLE III

STUdied Hydrogenerator's PARAMETER VALUES

\begin{tabular}{clcc}
\hline \hline Symbol & Description & Designed & Measured \\
\hline$R_{a}$ & Armature resistance & $0.002 \mathrm{pu}$ & \\
$X_{d}$ & Direct axis reactance & $1.087 \mathrm{pu}$ & $1.059 \mathrm{pu}$ \\
$X_{q}$ & Quadrature axis reactance & $0.676 \mathrm{pu}$ & \\
$X_{p}$ & Potier reactance & $0.144 \mathrm{pu}$ & $0.141 \mathrm{pu}$ \\
$X_{l}$ & Leakage axis reactance & $0.080 \mathrm{pu}$ & \\
\hline \hline
\end{tabular}

\section{Case Study and Main Results}

This section presents the case study and the main results used to emphasize the paper's contributions, which is the impact the energy transition has on the hydro-generator facilities. In Table II] the key quantities describing a 103 MVA Norwegian hydro generator is listed. There is also a list of designed and measured machine characteristics in Table III Finally, the determination of losses and the corresponding efficiency was conducted according to the IEEE 115, 7.2.4 method $4[20]$ as three separate off-grid heat-run tests: $(a)$ open, (b) short circuit, and (c) zero excitation, where some of the results are listed in Table IV] The same generator facility has been thermally investigated in an earlier six-hour heat run test (grid-connected) to identify rated load temperature rises [22]. Alternatively, an infrared thermal imaging technique could have been employed [23].

\section{A. Experimental Validation of Efficiencies and Saturation}

Eight on-site measurements verifying the loss model at different operations are documented in Table IV] An isoefficiency map of our model was then plotted together with the measured efficiencies in Fig. 4 The calculated non-concentric curves from eqs. (2)-(5) show a good agreement with the measured operating points of Table IV, as indicated in Fig. 4 From the outputs, the power loss contours are also plotted (in Fig. 5). This additional map is needed to conduct the proposed AAE, which is different from the alternative WAE. It was found that the most sensitive loss contribution was the saturation model, which predicts $I_{f}$ and relates to the exciter and rotor related losses. In Table $\mathrm{V}$, the accuracy of this model 


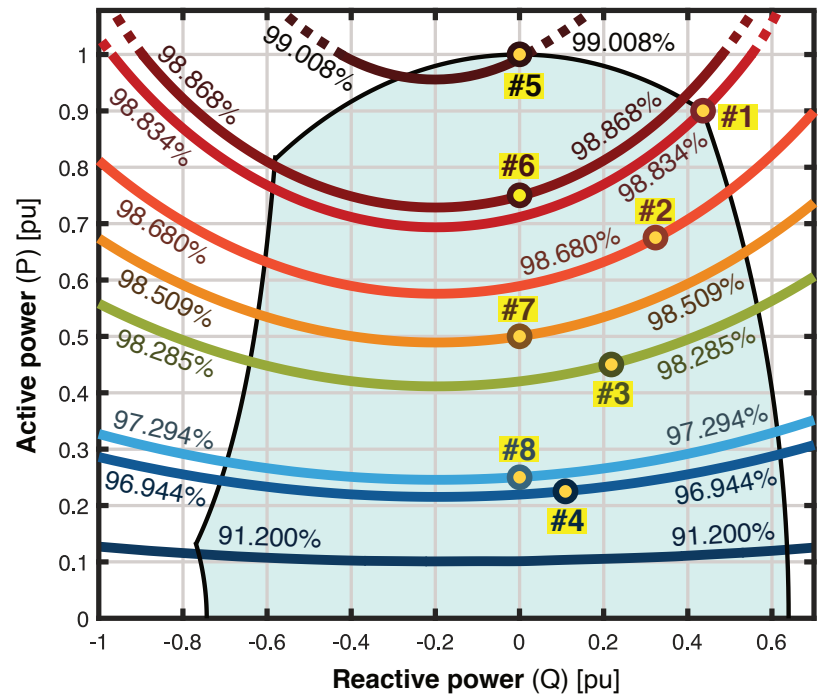

Fig. 4. Mapping of the calculated iso-efficiency curves of the capability diagram of the $103 \mathrm{MVA}$ synchronous machine, and assessed against eight measured operating points (referring to Table IV). $S_{\max }=1 \mathrm{pu}$. The left side of the capability diagram's boundary has $20 \%$ stability margin from the theoretical stability limit.

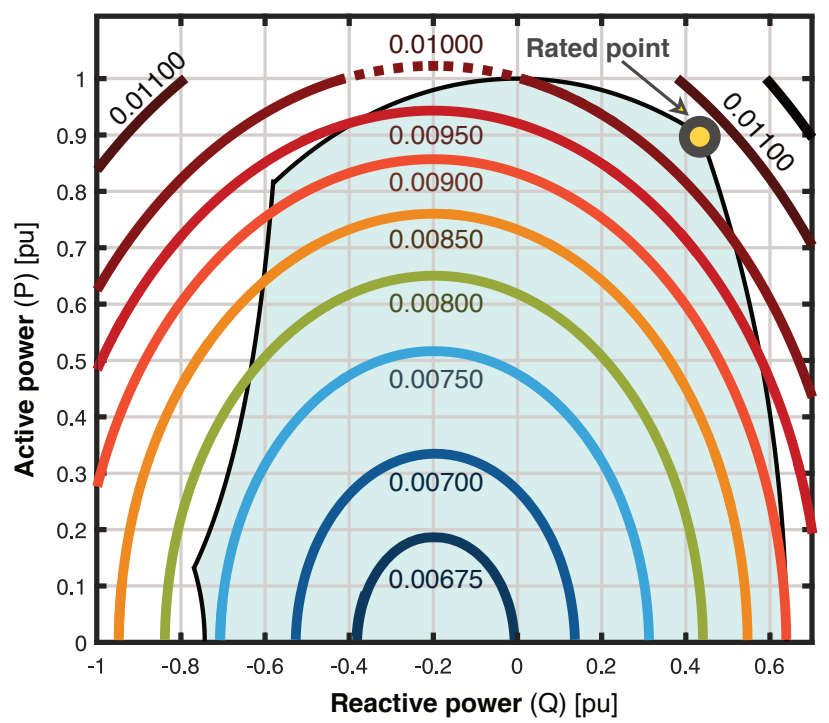

Fig. 5. Mapping of the calculated power loss contours over the capability diagram of the $103 \mathrm{MVA}$ synchronous machine in per unit with $103 \mathrm{MVA}$ as the power base.

was assessed against the measurements, revealing a worst-case deviation of $1.79 \%$, occurring in measurement number $\# 5$.

\section{B. Worked Example Assessing AAE Against WAE}

The method which provided the the post-processed isocurves presented in the last subsection will now be used as a basis to compare the proposed AAE against the alternative WAE in a worked example. For simplicity, six distinct operating points are considered throughout a whole year of operation. The handpicked load points are given in Table VI. specifying their output metrics. Finally, the individual load point's outputs are used to compare the AAE against the WAE in Table VII Notice that this is a simple example to demonstrate the core principles of the calculation models and not actual yearly production. I.e., the results presented are used to offer valuable insight into what differentiates the calculation models. The analytical calculation presented can also be easily reproduced by hand, which ensures the integrity of our work. The WEA is given by eq. 8 and calculated using eq. (24).

$$
\begin{aligned}
\eta_{w} & =\eta_{1} A_{1}+\eta_{2} A_{2}+\eta_{3} A_{3}+\eta_{4} A_{4}+\eta_{5} A_{5}+\eta_{6} A_{6} \\
& =\frac{0}{6}+\frac{0}{6}+\frac{98.509}{6}+\frac{98.215}{6}+\frac{99.011}{6}+\frac{98.886}{6}=65.77 \%
\end{aligned}
$$

Moreover, the AAE is given by eq. 19. Herein, the mean power $(\bar{P})$ is inserted to be $0.5 \mathrm{pu}$ from eq. $(16)$ and the mean power loss $\left(\bar{P}_{\text {loss }}\right)$ is found to be $0.00887 \mathrm{pu}$ from eq. 17 . Using eq. 20], the AAE efficiency is then found to be

$$
\eta_{a}=\frac{\bar{P}}{\bar{P}+\bar{P}_{\text {loss }}}=\frac{0.5}{0.5+0.00887}=98.256 \% .
$$

In general, it can be seen that the efficiency difference between $\eta_{a}$ and the alternative $\eta_{w}$ is $33.18 \%$ for this primitive example. The huge deviation is explained by the worked example's subsequent long periods operating at $P=0$ pu, i.e., at zero efficiencies $(\eta=0 \%)$. It is far from surprising, as the WAE is reduced proportionally to the amount of time the generator operates in SCM, as already predicted by eq. (11). The example provides preliminary theoretical support for the superiority of the proposed AAE approach. The same approaches will now be analyzed with more complex datasets and measured data in the next subsections.

\section{Sensitivity of Even Load Distribution's Number of Elements}

Expanding on the worked example, Fig. 6 shows two more complex load distributions that are more computationally demanding. The first one $(a)$ is the evenly distributed case, and the other one $(b)$ is a case of uniform distribution above $0.02 \mathrm{pu}$ active power, in addition to being dominated by load operations mimicking a synchronous condenser operation below 0.02 pu. In Fig. 6-(b), the generator operates $60.5 \%$ of the time in SCM mode. The overall results of this study are included in the final comparison presented in Table IX below.

For simplicity, the load operations in the even regions are equally distributed throughout the capability diagram. The evenly distributed case was studied as a function of the number of elements $(N)$ inside the capability diagram in Fig. 7 As $N$ is increasing, both the AAE and the WAE are shown to converge toward asymptotic values that are presented in Table VIII A deviation between the AAE and WAE is found to be $1.43 \%$. The AAE and WAE behave similarly with very few elements, but the weighting of the AAE and the WAE begins to diverge with higher $N$. This is because more elements will now be placed closer to the boundary of the synchronous condenser operations, where the efficiency is steeply approaching zero. 
TABLE IV

ON-SITE MEASURED QUANTITIES AT EIGHT DISTINCT LOAD POINTS FOR THE 103 MVA MACHINE USED FOR THE EFFICIENCY ANALYSIS IN FIG.5. WHERE THE NUMBER AND CORRESPONDING LOAD POINT AND EFFICIENCY IS HIGHLIGHTED.

\begin{tabular}{|c|c|c|c|c|c|c|c|c|}
\hline Output & $\# 1$ & \#2 & $\# 3$ & \#4 & $\# 5$ & \#6 & \#7 & $\# 8$ \\
\hline$S$ & $1.000 \mathrm{pu}$ & $0.750 \mathrm{pu}$ & $0.500 \mathrm{pu}$ & $0.250 \mathrm{pu}$ & $1.000 \mathrm{pu}$ & $0.750 \mathrm{pu}$ & $0.500 \mathrm{pu}$ & $0.250 \mathrm{pu}$ \\
\hline $\cos (\varphi)$ & 0.900 & 0.900 & 0.900 & 0.900 & 1.000 & 1.000 & 1.000 & 1.000 \\
\hline$P$ & $0.900 \mathrm{pu}$ & $0.675 \mathrm{pu}$ & $0.450 \mathrm{pu}$ & $0.225 \mathrm{pu}$ & $1.000 \mathrm{pu}$ & $0.750 \mathrm{pu}$ & $0.500 \mathrm{pu}$ & $0.250 \mathrm{pu}$ \\
\hline$Q$ & $0.436 \mathrm{pu}$ & $0.327 \mathrm{pu}$ & $0.218 \mathrm{pu}$ & $0.109 \mathrm{pu}$ & $0.000 \mathrm{pu}$ & $0.000 \mathrm{pu}$ & $0.000 \mathrm{pu}$ & $0.000 \mathrm{pu}$ \\
\hline$I_{a}$ & $5406.1 \mathrm{~A}$ & $4054.6 \mathrm{~A}$ & $2703.0 \mathrm{~A}$ & $1351.5 \mathrm{~A}$ & $5406.1 \mathrm{~A}$ & $4054.6 \mathrm{~A}$ & $2703.0 \mathrm{~A}$ & $1351.5 \mathrm{~A}$ \\
\hline$I_{f}$ & $1065.00 \mathrm{~A}$ & $936.12 \mathrm{~A}$ & $816.18 \mathrm{~A}$ & $711.38 \mathrm{~A}$ & $873.17 \mathrm{~A}$ & $776.61 \mathrm{~A}$ & $698.70 \mathrm{~A}$ & $646.84 \mathrm{~A}$ \\
\hline$P_{f}$ & $173.65 \mathrm{~kW}$ & $133.66 \mathrm{~kW}$ & $101.61 \mathrm{~kW}$ & $77.19 \mathrm{~kW}$ & $116.29 \mathrm{~kW}$ & $91.99 \mathrm{~kW}$ & $74.48 \mathrm{~kW}$ & $63.81 \mathrm{~kW}$ \\
\hline$P_{e x}$ & $15.88 \mathrm{~kW}$ & $13.02 \mathrm{~kW}$ & $10.72 \mathrm{~kW}$ & $8.87 \mathrm{~kW}$ & $11.65 \mathrm{~kW}$ & $9.92 \mathrm{~kW}$ & $8.68 \mathrm{~kW}$ & $7.92 \mathrm{~kW}$ \\
\hline$P_{b r}$ & $2.13 \mathrm{~kW}$ & $1.87 \mathrm{~kW}$ & $1.63 \mathrm{~kW}$ & $1.42 \mathrm{~kW}$ & $1.75 \mathrm{~kW}$ & $1.55 \mathrm{~kW}$ & $1.40 \mathrm{~kW}$ & $1.29 \mathrm{~kW}$ \\
\hline$P_{a}$ & $187.46 \mathrm{~kW}$ & $105.45 \mathrm{~kW}$ & $46.86 \mathrm{~kW}$ & $11.72 \mathrm{~kW}$ & $187.46 \mathrm{~kW}$ & $105.45 \mathrm{~kW}$ & $46.86 \mathrm{~kW}$ & $11.72 \mathrm{~kW}$ \\
\hline$P_{s}$ & $89.16 \mathrm{~kW}$ & $50.15 \mathrm{~kW}$ & $22.30 \mathrm{~kW}$ & $5.57 \mathrm{~kW}$ & $89.16 \mathrm{~kW}$ & $50.15 \mathrm{~kW}$ & $22.30 \mathrm{~kW}$ & $5.57 \mathrm{~kW}$ \\
\hline$P_{c}$ & $211.92 \mathrm{~kW}$ & $211.92 \mathrm{~kW}$ & $211.92 \mathrm{~kW}$ & $211.92 \mathrm{~kW}$ & $211.92 \mathrm{~kW}$ & $211.92 \mathrm{~kW}$ & $211.92 \mathrm{~kW}$ & $211.92 \mathrm{~kW}$ \\
\hline$P_{b e}$ & $240.90 \mathrm{~kW}$ & $240.90 \mathrm{~kW}$ & $240.90 \mathrm{~kW}$ & $240.90 \mathrm{~kW}$ & $240.90 \mathrm{~kW}$ & $240.90 \mathrm{~kW}$ & $240.90 \mathrm{~kW}$ & $240.90 \mathrm{~kW}$ \\
\hline$P_{w f}$ & $172.92 \mathrm{~kW}$ & $172.92 \mathrm{~kW}$ & $172.92 \mathrm{~kW}$ & $172.92 \mathrm{~kW}$ & $172.92 \mathrm{~kW}$ & $172.92 \mathrm{~kW}$ & $172.92 \mathrm{~kW}$ & $172.92 \mathrm{~kW}$ \\
\hline$P_{\text {loss }}$ & $1094.02 \mathrm{~kW}$ & $921.89 \mathrm{~kW}$ & $808.85 \mathrm{~kW}$ & $730.51 \mathrm{~kW}$ & $1032.05 \mathrm{~kW}$ & $884.81 \mathrm{~kW}$ & $779 \mathrm{~kW}$ & $172.92 \mathrm{~kW}$ \\
\hline$\eta$ & $98.834 \%$ & $98.680 \%$ & $98.250 \%$ & $96.944 \%$ & $99.008 \%$ & $98.868 \%$ & $98.509 \%$ & $97.294 \%$ \\
\hline
\end{tabular}

TABLE V

VALIDATION OF THE SATURATION MODEL FOR THE EIGHT DISTINCT LOAD POINTS PRESENTED IN TABLEIV] USING EQ. 23 ,

\begin{tabular}{lcccccccc}
\hline \hline Output & $\mathbf{\# 1}$ & $\mathbf{\# 2}$ & $\mathbf{\# 3}$ & $\mathbf{\# 4}$ & $\mathbf{\# 5}$ & $\mathbf{\# 6}$ & $\mathbf{\#}$ & $\mathbf{\# 8}$ \\
\hline Measured $I_{f}$ & $1065.00 \mathrm{~A}$ & $936.12 \mathrm{~A}$ & $816.18 \mathrm{~A}$ & $711.38 \mathrm{~A}$ & $873.17 \mathrm{~A}$ & $776.61 \mathrm{~A}$ & $698.70 \mathrm{~A}$ & $646.84 \mathrm{~A}$ \\
Calculated $I_{f u}$ & $907.99 \mathrm{~A}$ & $794.05 \mathrm{~A}$ & $689.23 \mathrm{~A}$ & $597.70 \mathrm{~A}$ & $747.18 \mathrm{~A}$ & $657.57 \mathrm{~A}$ & $586.96 \mathrm{~A}$ & $541.21 \mathrm{~A}$ \\
Calculated $I_{f}$ & $1064.88 \mathrm{~A}$ & $934.23 \mathrm{~A}$ & $815.01 \mathrm{~A}$ & $711.11 \mathrm{~A}$ & $857.50 \mathrm{~A}$ & $764.76 \mathrm{~A}$ & $691.88 \mathrm{~A}$ & $644.67 \mathrm{~A}$ \\
\hline Deviation $I_{f}$ & $-0.01 \%$ & $-0.20 \%$ & $-0.14 \%$ & $-0.03 \%$ & $-1.79 \%$ & $-1.52 \%$ & $-0.97 \%$ & $-0.34 \%$ \\
\hline \hline
\end{tabular}

TABLE VI

WORKED EXAMPLE OF GENERATOR OPERATING IN SIX DISTINCT LOAD POINTS OVER A YEAR

\begin{tabular}{lccccccc}
\hline \hline Output & $\mathbf{\# 1}$ & $\mathbf{\# 2}$ & $\mathbf{\# 3}$ & $\mathbf{\# 4}$ & $\mathbf{\# 5}$ & $\mathbf{\# 6}$ & Sum \\
\hline$P_{i}$ & $0.0 \mathrm{pu}$ & $0.0 \mathrm{pu}$ & $0.5 \mathrm{pu}$ & $0.5 \mathrm{pu}$ & $1.0 \mathrm{pu}$ & $1.0 \mathrm{pu}$ & \\
$Q_{i}$ & $0.0 \mathrm{pu}$ & $0.5 \mathrm{pu}$ & $0.0 \mathrm{pu}$ & $0.5 \mathrm{pu}$ & $0.0 \mathrm{pu}$ & $0.5 \mathrm{pu}$ & \\
$\Delta t_{i}$ & $1460 \mathrm{~h}$ & $1460 \mathrm{~h}$ & $1460 \mathrm{~h}$ & $1460 \mathrm{~h}$ & $1460 \mathrm{~h}$ & $1460 \mathrm{~h}$ & $8760 \mathrm{~h}$ \\
$A_{i}$ & $1 / 6$ & $1 / 6$ & $1 / 6$ & $1 / 6$ & $1 / 6$ & $1 / 6$ & 1 \\
$P_{\text {loss }, i}$ & $0.00676 \mathrm{pu}$ & $0.00827 \mathrm{pu}$ & $0.00757 \mathrm{pu}$ & $0.009089 \mathrm{pu}$ & $0.00999 \mathrm{pu}$ & $0.011537 \mathrm{pu}$ & \\
$\eta_{i}$ & $0 \%$ & $0 \%$ & $98.509 \%$ & $98.215 \%$ & $99.011 \%$ & $98.886 \%$ & \\
$E_{i}$ & $0.00 \mathrm{GWh}$ & $0.00 \mathrm{GWh}$ & $75.19 \mathrm{GWh}$ & $75.19 \mathrm{GWh}$ & $150.38 \mathrm{GWh}$ & $150.38 \mathrm{GWh}$ & $451.14 \mathrm{GWh}$ \\
$E_{\text {loss }, i}$ & $1.017 \mathrm{GWh}$ & $1.244 \mathrm{GWh}$ & $1.138 \mathrm{GWh}$ & $1.367 \mathrm{GWh}$ & $1.503 \mathrm{GWh}$ & $1.735 \mathrm{GWh}$ & $8.004 \mathrm{GWh}$ \\
\hline \hline
\end{tabular}

TABLE VII

FINAL OUTPUTS FROM WORKED EXAMPLE WITH SIX DISTINCT LOAD POINTS OVER A YEAR

\begin{tabular}{|c|c|c|c|c|c|c|c|c|c|}
\hline Value & $\begin{array}{c}E \\
451.14 \mathrm{GWh}\end{array}$ & $\begin{array}{c}E_{\text {loss }} \\
8.004 \mathrm{GWh}\end{array}$ & $\begin{array}{c}\bar{P} \\
0.50000 \mathrm{pu}\end{array}$ & \begin{tabular}{|c|}
$\bar{P}_{\text {loss }}$ \\
$0.00887 \mathrm{pu}$
\end{tabular} & $\begin{array}{c}\eta_{w} \\
65.766 \%\end{array}$ & $\begin{array}{c}\eta_{w}-\eta_{n} \\
-33.068 \%\end{array}$ & $\begin{array}{c}\eta_{a} \\
98.257 \%\end{array}$ & $\begin{array}{c}\eta_{a}-\eta_{n} \\
-0.577 \%\end{array}$ & $\begin{array}{c}\eta_{a}-\eta_{w} \\
+32.491 \%\end{array}$ \\
\hline
\end{tabular}

TABLE VIII

FINAL OUTPUTS FROM EVEN LOAD DISTRIBUTION OVER A WHOLE YEAR WITH 179851 NUMBER OF ELEMENTS (N)

\begin{tabular}{|c|c|c|c|c|c|c|c|c|c|}
\hline Value & $\begin{array}{c}E \\
404.927 \mathrm{GWh}\end{array}$ & $\begin{array}{c}E_{\text {loss }} \\
7.248 \mathrm{GWh}\end{array}$ & $\begin{array}{c}\bar{P} \\
0.44878 \mathrm{pu}\end{array}$ & $\frac{\bar{P}_{\text {loss }}}{0.00803 \mathrm{pu}}$ & $\begin{array}{c}\eta_{w} \\
95.923 \%\end{array}$ & $\begin{array}{c}\eta_{w}-\eta_{n} \\
-2.911 \%\end{array}$ & $\frac{\eta_{a}}{98.242 \%}$ & $\begin{array}{c}\eta_{a}-\eta_{n} \\
-0.592 \%\end{array}$ & $\begin{array}{c}\eta_{a}-\eta_{w} \\
+2.319 \%\end{array}$ \\
\hline
\end{tabular}

\section{Even Distribution with Power Constraints}

The characteristics of the AAE and WAE have also been tested for even distribution with different active power constraints. First, the maximum active power threshold was ramped from $0 \mathrm{pu}$ to $1 \mathrm{pu}$, which is illustrated in Fig. 8 . At unity maximum power, the efficiencies are equal to what is reported in Table VIII and the asymptotic values of Fig. 7. The disparities between the AAE and the WAE are greatest at active power levels from 0 to $0.3 \mathrm{pu}$ and highlights that the
WAE is an insufficient model for low power levels, contrary to the AAE. However, both models have low efficiency as the threshold approaches zero.

In Fig. 9, a minimum active power threshold is ramped from 0.99 to $0 \mathrm{pu}$. In general, WAE is revealed to be a good model for load operations with a relatively high minimum active power threshold. However, as one lowers the minimum power threshold, the value converges to its uniform distribution value, as mentioned earlier, clearly deviating from the AAE. 
Probability of occurrence [\%]
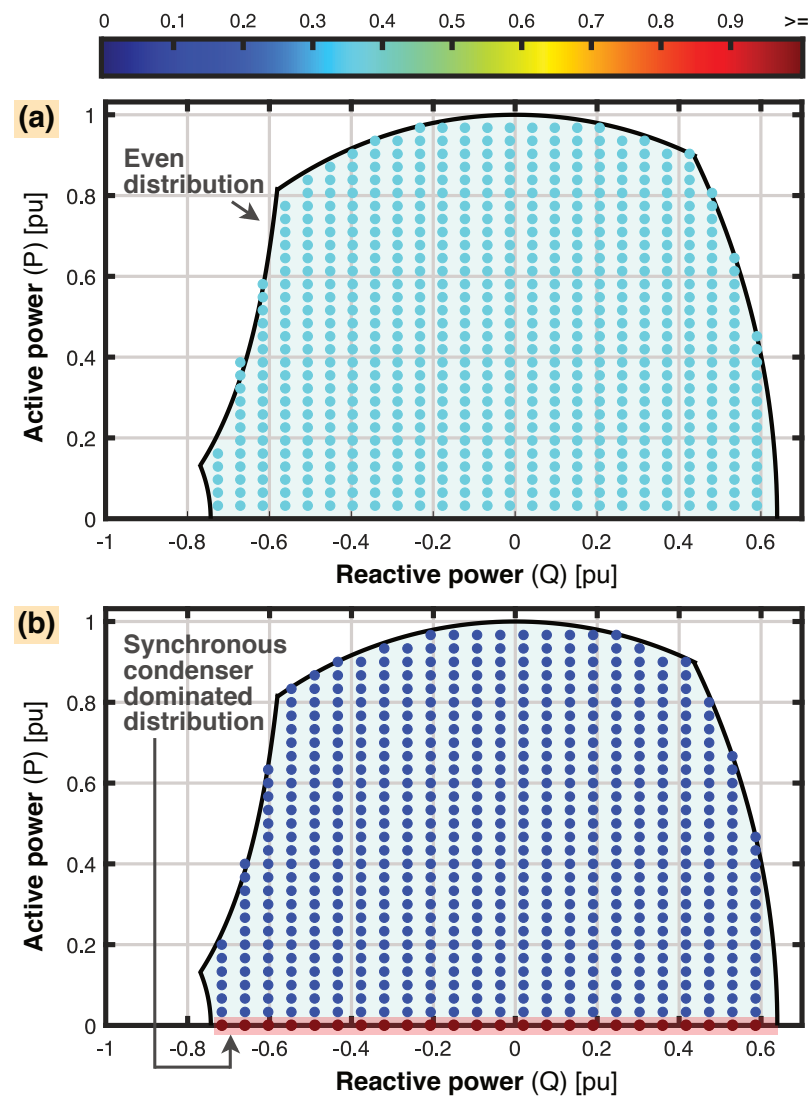

Fig. 6. Two-dimensional histograms for the probability of occurrence of different intermittent load operations that are artificially made as worst-case scenarios, i.e., a uniform load distribution (641 elements) and a synchronous condenser dominated distribution (623 elements), respectively. The theoretica limits go beyond the changes reported in [1] and [7], to expand on the consequences of RES, which are further summarized in Table IX.

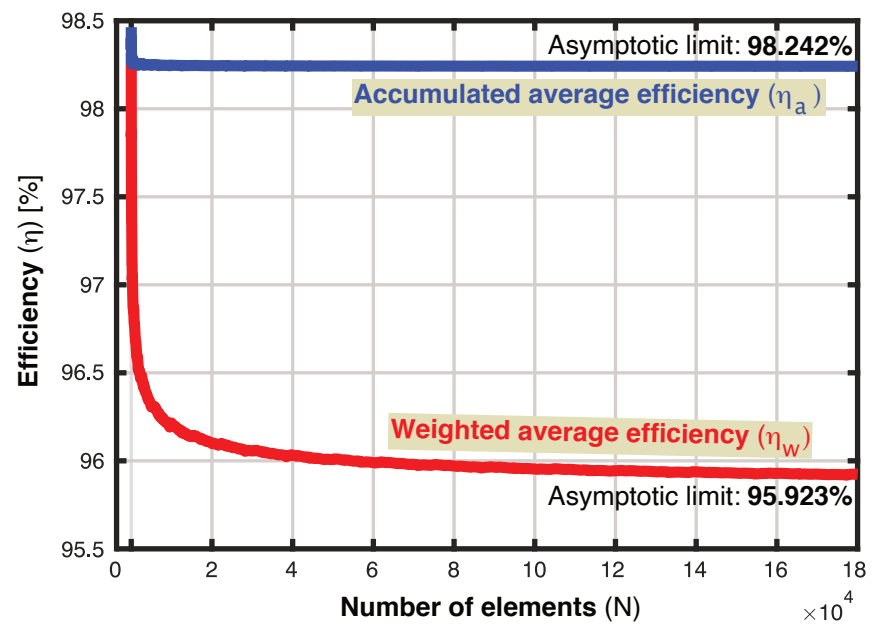

Fig. 7. Weighted average efficiency $\left(\eta_{w}\right)$ and accumulated average efficiency $\left(\eta_{a}\right)$ as a function of number of elements for even load distribution over the capability diagram of the 103 MVA hydrogenerator, referring to Fig. 2

\section{E. Concentrated Distribution Case from On-Site Measure- ments}

In [1], the WAE is calculated using approximated zones of load operations. In other words, the zone consist of all the

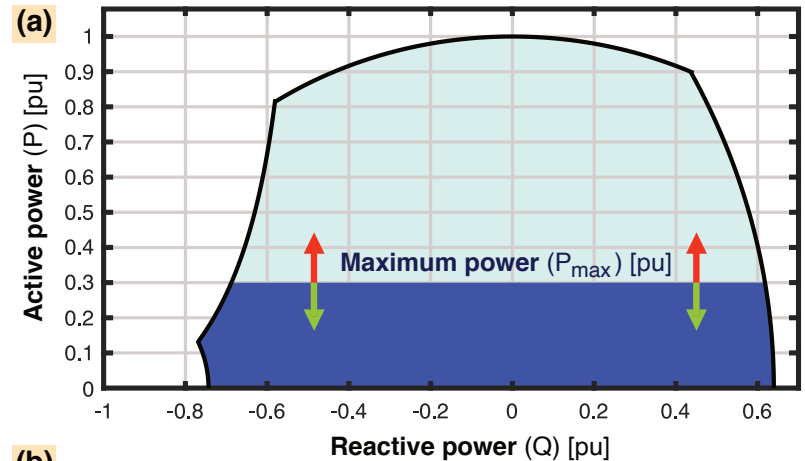

(b)

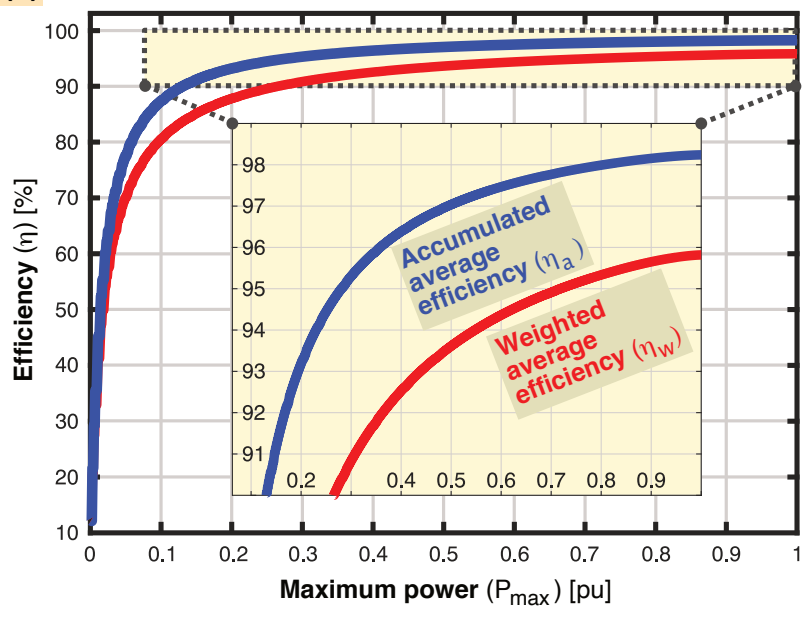

Fig. 8. Weighted average efficiency $\left(\eta_{w}\right)$ and accumulated average efficiency $\left(\eta_{a}\right)$ as a function of maximum power for even load distribution over the capability diagram of the 103 MVA synchronous machine. a): Definition of the maximum power $\left(P_{\max }\right)$ with the dark blue area covering the evenly distributed load points. b): Efficiencies $\left(\eta_{w}\right.$ and $\left.\eta_{a}\right)$ plotted in terms of $P_{\max }$, converging toward the values presented in Table VIII as $P_{\max }$ approaches $1 \mathrm{pu}$. The maximum number of elements (N) where 171075.

exact load operations rounded up to discrete load points. This means that the histogram does not show all the distinct load operations. In Fig. 10, the exact load operations are presented in a scatter plot that highlights the density of the occurring load operations. The probability of occurrence is determined based on the proximity of the exact load points. This means that the histogram does not show the probability of an exact loading but rather the likelihood of a discrete load point occurring in a certain region.

The concentrated load distribution gathered from a year of on-site measurements provides the most similar efficiency levels, comparing the AAE and the WAE. The difference in efficiency was found to be $0.67 \%$. This is because, in this distribution, a lot of the load operations are concentrated around $P_{\max }$ and operate in a relatively small area. Moreover, the generator is rarely operated in SCM. Still, $0.67 \%$ difference is a major difference between the AEE and the WAE when considering the economic implications of this difference, if the WAE would be considered as physical. A final comparison that summarizes the findings are provided in Table IX.

\section{CONCLUSION}

A new method to determine the overall operating efficiency of synchronous generators under intermittent operation 
TABLE IX

THE AAE AND THE WAE FOR THE DIFFERENT LOAD DISTRIBUTION PRESENTED IN FIGS.10]AND 6

\begin{tabular}{|c|c|c|c|c|c|c|c|c|}
\hline Distribution & $E$ & $E_{\text {loss }}$ & $\bar{P}$ & $\bar{P}_{\text {loss }}$ & $\eta_{\mathrm{w}}$ & $\eta_{\mathrm{a}}$ & $\eta_{\mathrm{a}}-\eta_{\mathrm{w}}$ & $\mathrm{N}$ \\
\hline Concentrated load distribution $^{1}$ (measured) & $652.175 \mathrm{GWh}$ & $7.715 \mathrm{GWh}$ & $0.7354 \mathrm{pu}$ & $0.0087 \mathrm{pu}$ & $98.17 \%$ & $98.83 \%$ & $+0.67 \%$ & 8610 \\
\hline Synchronous condenser-dominated distribution ${ }^{3}$ & $165.98 \mathrm{GWh}$ & $6.82 \mathrm{GWh}$ & $0.1840 \mathrm{pu}$ & 0.0076 & $62.87 \%$ & $96.05 \%$ & $+33.18 \%$ & 623 \\
\hline
\end{tabular}

${ }^{1}$ Elements are not discrete but measured every hour for $8610 \mathrm{~h} ;{ }^{2}$ Operates $8760 \mathrm{~h}$ with equal weight for every element (Fig. $6 \mathrm{a}$ ); ${ }^{3}$ Operates $8760 \mathrm{~h}$ with higher probability of occurance in SCM (Fig. 6b). The WAE is $62.87 \%$ and not lowered as much as theoretically expected since $P$ is not set exactly to zero during the SCM operation, i.e, $P$ was 0.004895 pu, yielding a mean SCM efficiency $\left(\eta_{s c m}\right)$ of $40.5354 \%$ during $60.5 \%$ of its operational time.
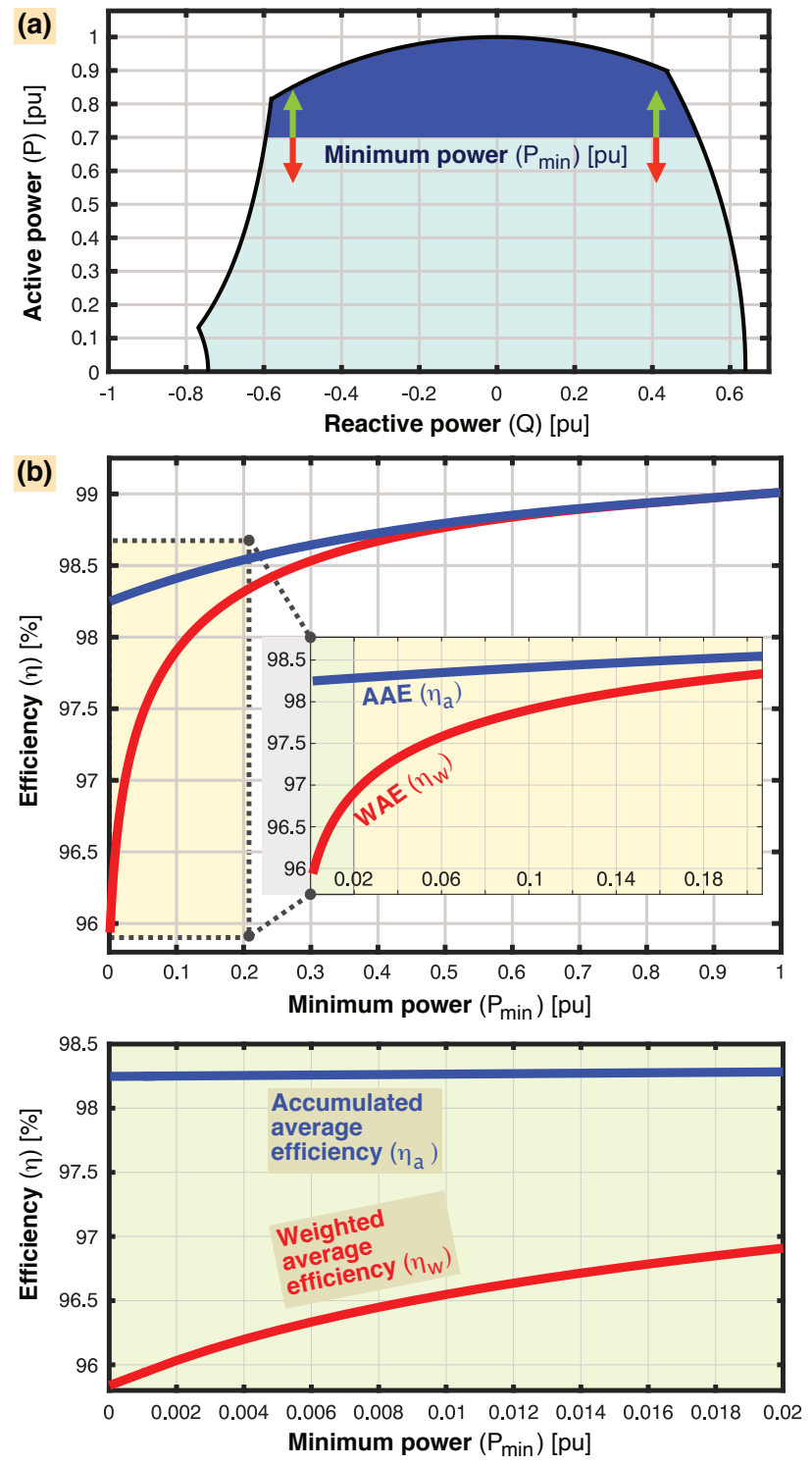

Fig. 9. Weighted average efficiency $\left(\eta_{w}\right)$ and accumulated average efficiency $\left(\eta_{a}\right)$ as a function of minimum power for even load distribution over the capability diagram of the 103 MVA synchronous machine. a): Definition of the minimum power $\left(P_{\min }\right)$ with the dark blue area covering the evenly distributed load points. b): Efficiencies $\left(\eta_{w}\right.$ and $\left.\eta_{a}\right)$ plotted in terms of $P_{\min }$ converging toward the values presented in Table VIII as $P_{\min }$ approaches $0 \mathrm{pu}$. The maximum number of elements $(\mathrm{N})$ where 171075 .

is proposed, where the machine's magnetic saturation has been incorporated. It is shown that the proposed AAE is more effective and adaptable than the alternative WAE for all the different load distributions that were investigated. The AAE is, therefore, a necessary tool to quantify a generator's overall efficiency accurately in future operating regimes. To legitimize the results, our efficiency and loss map has been validated by eight handpicked load-point measurements. The following findings comparing the $\mathrm{AAE}$ and the WAE have been identified.

1) A load distribution dominated by SCM yields a difference as high as $33.18 \%$, while an even distribution deviates by $1.43 \%$ in their respective efficiencies;

2) A concentrated load distribution found from a full year of measurements on the studied generator revealed a discrepancy of $0.67 \%$, which is a significant deviation considering what the operating regime would mean in terms of economic implications. E.g., designing a generator with $98.17 \%$ compared to $98.83 \%$ could yield a significant discrepancy in return on investment over the generators lifetime.

3) It is perceived that there is no physical relevance to the significant reduction in the WAE. This paper compares the WAE against the AAE and shows that the WAE is much more heavily influenced by the weight coefficients and by intervals of low active power.

Finally, this paper prepares for a wide spectrum of further research. The additional costs for intermittent operation of hydrogenerators should not merely be investigated in terms of losses, but also its implication on the generator's lifetime. The burden is not only influenced by the static load points, but also by the rapid transitions between them. Future work should also investigate how the loading regime could be better incorporated into the design of hydrogenerators from scratch.

\section{REFERENCES}

[1] E. d. C. Bortoni, R. T. Siniscalchi, S. Vaschetto, M. A. Darmani, and A. Cavagnino, "Efficiency mapping and weighted average efficiency for large hydrogenerators," IEEE Open J. Ind. Appl., vol. 2, pp. 11-20, 2021.

[2] "REPORT ON COORDINATION OF GRID CODES AND GENERATOR STANDARDS: Consequences of diverse grid code requirements an synchronous machine design and standards," Technical report PESTR69, pp. 1-88, Feb 2019.

[3] E. C. Bortoni, M. K. I. Uemori, B. T. Araujo, J. V. Bernardes, J. J. Rocha E., and R. T. Siniscalchi, "Accurate methodology to obtain efficiency mapping of synchronous machines," in Proc. IEEE Power \& Energy Soc. Gen. Meeting (PESGM), 2020, pp. 1-5.

[4] A. Nami, "Power electronics for future power grids: Drivers and challenges," in 2018 20th European Conference on Power Electronics and Applications (EPE'18 ECCE Europe), 2018, pp. P.1-P.2.

[5] J.-H. Braam, "Development, test and validation of new generator product line for current and future operational regimes," 2018.

[6] A. Joswig, K. Walli, and M. Baca, "Synchronous rotating equipment as backbone for renewables," in VDE High Voltage Technology 2018; ETG-Symposium. VDE, 2018, pp. 1-6. 

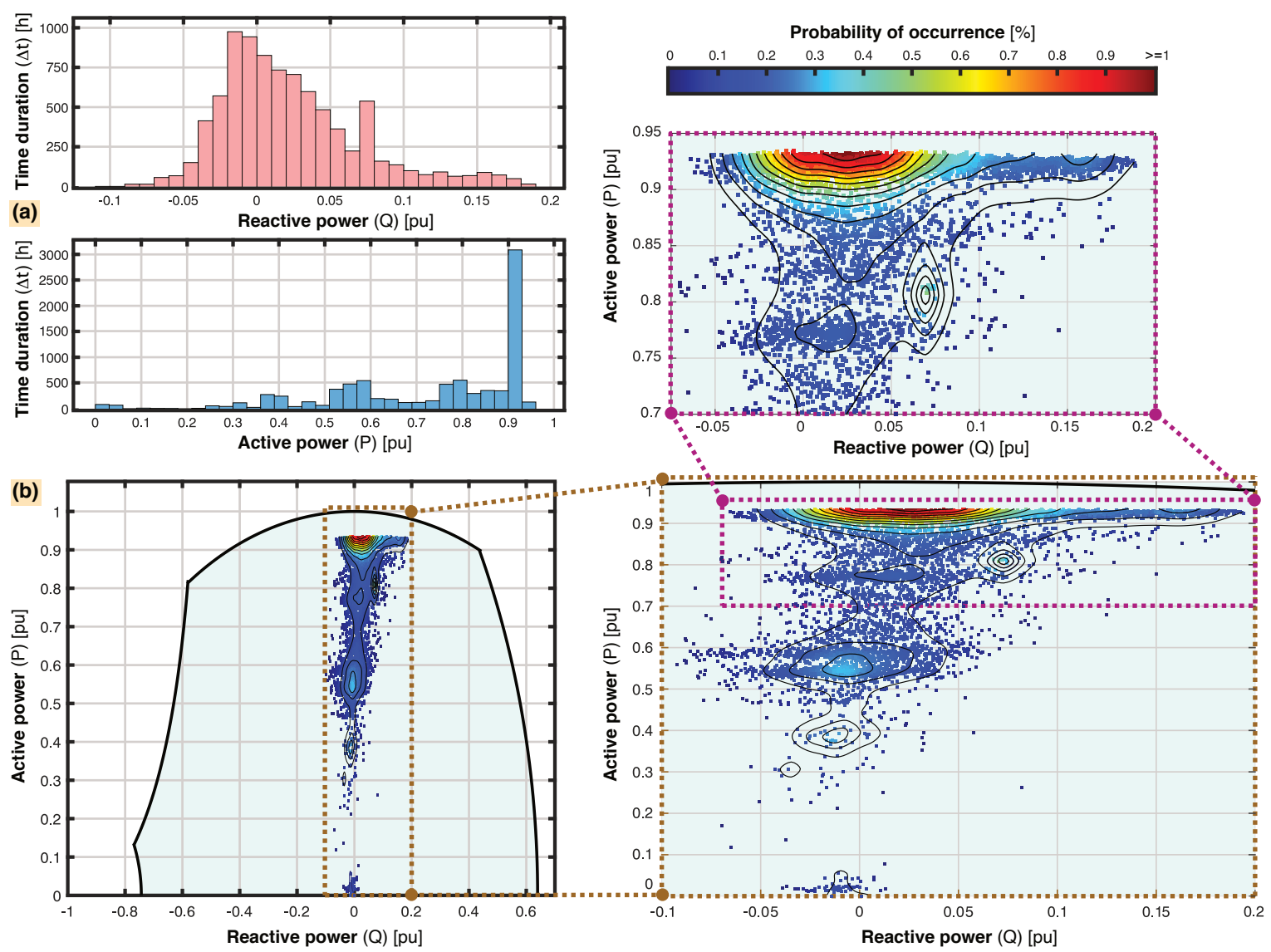

Fig. 10. Load distributions for a whole year of the studied hydropower plant (concentrated load dis.). The minimum and maximum reactive power ranges from -0.08 to $0.2 \mathrm{pu}$. The minimum and maximum active power are varying from 0 to $1 \mathrm{pu}$. The measurements were recorded every hour, starting from 06. January 2020 15:00, ending at 31 . December 2020 (i.e., $8610 \mathrm{~h}$ in total). The generator were operated $3087 \mathrm{~h}$ around the vicinity of the $P_{\max }$ region. Contour lines are added to indicate the density peaks. a): One-dimensional histogram of number of hours $(\Delta t)$. b): Two-dimensional histogram of probability of occurrence in percent $(\%)$.

[7] J. K. Nøland, M. Leandro, A. Nysveen, and T. Øyvang, "Future operational regimes of bulk power generation in the era of global energy transition: Grid codes, challenges and open issues," in Proc. IEEE Power Energy Soc. Gen. Meet. (PESGM), 2020, pp. 1-5.

[8] W. Tang, J. Hu, Y. Chang, and X. Kong, "Short-circuit current of gridconnected voltage source converters: Multi-timescale analysis method," in Proc. IEEE PES GM, July 2017, pp. 1-5.

[9] T. Øyvang, J. K. Nøland, R. Sharma, G. J. Hegglid, and B. Lie, "Enhanced power capability of generator units for increased operational security using NMPC," IEEE Trans. Power Syst., vol. 35, no. 2, pp. $1562-1571,2020$.

[10] C. Carounagarane, T. R. Chelliah, and D. Khare, "Analysis on thermal behavior of large hydrogenerators operating with continuous overloads," IEEE Trans. Ind. Appl., vol. 56, no. 2, pp. 1293-1305, 2020.

[11] T. Tellefsen, J. van Putten, and O. Gjerde, "Norwegian hydropower: Connecting to continental europe," IEEE Power and Energy Mag., vol. 18, no. 5, pp. 27-35, 2020.

[12] S. Wang, J. Liu, H. Chen, R. Bo, and Y. Chen, "Modeling state transition and head-dependent efficiency curve for pumped storage hydro in lookahead dispatch," IEEE Trans. Power Syst., pp. 1-1, 2021.

[13] W. Yang, P. Norrlund, L. Saarinen, A. Witt, B. Smith, J. Yang, and U. Lundin, "Burden on hydropower units for short-term balancing of renewable power systems," Nature Com., vol. 9, no. 1, pp. 1-12, 2018.

[14] F. Maurer and J. K. Nøland, "A rectangular end-winding model for enhanced circulating current prediction in ac machines," IEEE Trans. Energy Convers., vol. 36, no. 1, pp. 291-299, 2021.

[15] J. K. Nøland, S. Nuzzo, A. Tessarolo, and E. F. Alves, "Excitation system technologies for wound-field synchronous machines: Survey of solutions and evolving trends," IEEE Access, vol. 7, pp. 109699-109718, 2019.

[16] J. C. Akiror, P. Pillay, and A. Merkhouf, "Effect of saturation on rotational flux distribution in hydro generators," IEEE Trans. Energy Convers., vol. 31, no. 4, pp. 1657-1664, 2016.
[17] "COMMISSION REGULATION (EU) establishing a network code on requirements for grid connection of generators (NC-RfG)," THE EUROPEAN COMMISSION, p. 68, Apr 2016.

[18] "NVF 2020 National guide for functional requirements in the power system," Statnett, p. 240, Jul 2020.

[19] J. R. B. Jan Machowski; Zbigniew Lubosny, Janusz W. Bialek, Power system dynamics : stability and control, 3rd ed. Chichester: Wiley, 2020, iSBN:1119526345.

[20] "IEEE guide for test procedures for synchronous machines including acceptance and performance testing and parameter determination for dynamic analysis," IEEE Std 115-2019 (Revision of IEEE Std 115-2009), pp. 1-246, 2020.

[21] B. T. Araujo, M. S. Han, B. Kawkabani, and E. C. Bortoni, "Estimation of the armature leakage reactance using the constant excitation test," in Proc. XXII Int. Conf. Electr. Mach. (ICEM), 2016, pp. 313-317.

[22] T. Øyvang, J. K. Nøland, G. J. Hegglid, and B. Lie, "Online model-based thermal prediction for flexible control of an air-cooled hydrogenerator," IEEE Trans. Ind. Electron., vol. 66, no. 8, pp. 6311-6320, 2019.

[23] E. da Costa Bortoni, R. T. Siniscalchi, and J. A. Jardini, "Determination of hydro generator efficiency using infrared thermal imaging techniques," IEEE Trans. Energy Convers., vol. 26, no. 4, pp. 1134$1139,2011$. 


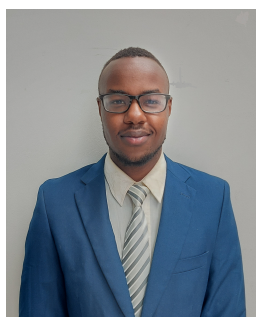

Yannick Cyiza Karekezi is currently finishing an MSc degree at the Norwegian University of Science and technology (NTNU). His research interests include saturation, salient-pole synchronous generators, and power system dynamics. He is currently a Board Member of the IEEE Power and Energy Society (PES) Norwegian Chapter.

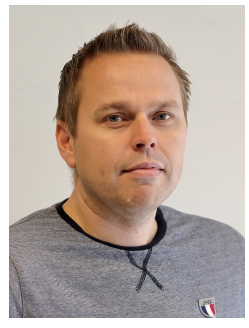

Thomas Øyvang (S'17-M'19) received the Ph.D. degree in Process, Energy and Automation from the University of South-Eastern Norway (USN) in 2018. Since January 2019 he has been an Associate Professor, and the R\&D manager for the research group Hydro Power, Transmission and Distribution with the USN, Porsgrunn. His research interests include control systems, salient-pole synchronous generators, and power system dynamics. Dr. Øyvang is a Board Member of the Norwegian Academic Committee of Publication in Technology.

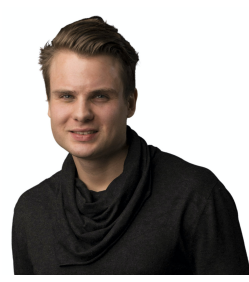

Jonas Kristiansen Nøland (S'14-M'17) was born in Drammen, Norway, in 1988. He received the M.Sc. degree in electric power engineering from the Chalmers University of Technology, Gothenburg, Sweden, in 2013, and the Ph.D. degree in engineering physics from Uppsala University, Uppsala, Sweden, in 2017. Since 2018, he has been an Associate Professor with the Department of Electric Power Engineering, Norwegian University of Science and Technology. His current research interests include excitation systems, hydrogenerators, large $\mathrm{AC}$ machines, and enhancing their utilization. Other interests are high-power machinery for aircraft applications, Hyperloop propulsion and levitation, and transportation electrification in general. Dr. Nøland serves as an Editor for the IEEE TRANSACTIONS ON ENERGY CONVERSION and as an Associate Editor for the IEEE TRANSACTIONS ON INDUSTRIAL ELECTRONICS. 